\title{
CIÊNCIA E TECNOLOGIA NO OLHAR DE BRUNO LATOUR
}

\begin{abstract}
Rubens da Silva Ferreira - rubenspa@yahoo.com Doutorando do Programa de Pós-graduação em Ciência da Informação (IBICT/UFRJ). Docente da Faculdade de Biblioteconomia da Universidade

Federal do Pará (UFPA).
\end{abstract}

LATOUR, Bruno. Ciência em ação: como seguir cientistas e engenheiros sociedade afora. Tradução de Ivone C. Benedetti. 2. ed. São Paulo: Editora UNESP, 2011. 422 p.

O olhar de Robert King Merton (1910-2003) sobre a comunidade científica, com suas práticas e valores - que se tornaram foco de investigação do que veio a ser denominado como Sociologia da Ciência nos anos de 1940 -, tem aberto um campo diversificado de possibilidades analíticas. Nesta perspectiva, as investigações circunscritas no quadro de referência dos estudos sociais da Ciência não residem no conhecimento científico em si, mas, na compreensão sobre seus produtores como sujeitos que, no entendimento de Merton, formam e são sustentados por um ethos próprio. Entre outros estudiosos que se consagraram investigando o fazer da comunidade científica, precisamente os cientistas ligados às Ciências Naturais, têm-se, por exemplo, Joseph Ben-David (1920-1986), Derek J. de Solla Price (1922-1983), Thomas Kuhn (1922-1996) e o francês Bruno Latour (1947...). Entre a produção intelectual deste último, esta resenha se ocupa da obra Ciência em ação, publicada originalmente em inglês, em 1987, e traduzida para as línguas francesa (1987), alemã (1988), espanhola (1992), italiana (1998), japonesa (1999), portuguesa (2000) e chinesa (2009).

Comparado aos estudos pioneiros da Sociologia da Ciência, Latour firma seu campo de investigação na Nova Sociologia da Ciência. Esta especialidade tem se configurado e adquirido forma desde a década de 1970 com o Strong Programme de David Bloor (1942- ), professor da Science Studies Unit na University of Edinburgh. Apesar de se dedicarem a um mesmo campo de estudo, eles não poupam críticas 
mútuas de ordem teórico-metodológica. Latour acusa o criador do Strong Programme de positivismo, de relativismo e de radicalismo excessivos nas pesquisas que realiza, assim como questiona a eficiência do princípio de simetria ao desconsiderar a possibilidade de desequilíbrio entre as forças que compõem a rede científica. Bloor, por sua vez, desqualifica o primeiro na abordagem construtivista de Ciência e na reformulação de Latour ao princípio de simetria, o que é deliberadamente desconstruído no artigo intitulado "Anti-Latour", publicado na revista Studies in History and Philosophy of Science, em 1999.

Com formação em Filosofia e Sociologia, atualmente trabalhando como docente, Assistente de Diretor e Diretor Científico na Sciences $\mathrm{Po}^{1}$, em Paris, Latour realizou estudos sociais sobre ciência e tecnologia orientados pela pesquisa etnográfica, tomando como campo o laboratório do Salk Institute for Biological Studies, na Califórnia. O produto de dois anos de observações está no livro Laboratory Life, publicado em coautoria com Steve Woolgar (1950- ), em 1979, tendo possivelmente fornecido as bases para os insights que estruturam o discurso de Latour em Ciência em ação.

$\mathrm{Na}$ obra em questão, Latour adota uma perspectiva construtivista para compreender o processo de produção da Ciência. Processo esse que envolve uma intrincada rede de elementos humanos (cientistas, engenheiros, colaboradores, aliados, discordantes, financiadores, burocratas, o cidadão comum etc.) e não humanos (literatura especializada, laboratórios, máquinas etc.) que podem ser observados em interação contínua. No plano da obra, esses elementos são discutidos em seis capítulos, distribuídos ao longo de três partes, sendo elas: I - Da retórica mais fraca a mais forte; II - Dos pontos fracos e fortes; e III - De pequenas a grandes redes. Assim, o objetivo central de Latour é estudar a Ciência no exato momento em que é feita, procurando desconstruir a imagem que a sociedade mais ampla possui sobre ela a partir dos produtos que é capaz de gerar, quais sejam teorias e/ou artefatos técnicos, ou, para usar uma terminologia antropológica, a cultura imaterial e material, resultante da práxis do que Latour denomina como tecnociência.

\footnotetext{
${ }^{1}$ http://pt.wikipedia.org/wiki/Sciences_Po
} 
O uso recorrente e metafórico de elementos da mitologia greco-romana tem função didática na orientação do leitor de Ciência em ação. Com efeito, e conforme Latour, o recurso ao deus romano Jano, de face dupla, representa não só duas estratégias de abordagem investigativa sobre a Ciência, como também as incertezas, as controvérsias, as escolhas a serem feitas e os discursos que se processam simultaneamente entre diferentes atores, envolvidos direta ou indiretamente na construção do conhecimento científico. A enigmática caixa-preta de Pandora só é desvelada ao público leigo em função da escolha metodológica de Latour: observá-la antes que seja "fechada". Como ele mesmo explica, o ingresso que faz "no mundo da ciência e da tecnologia [dá-se] pela porta de trás", o que permite compreender os mecanismos complexos que operam a construção do conhecimento científico em seus bastidores, espaços em que são engendradas as tramas, as afirmações, as competições, as (des)informações, os fatos, a construção dos artefatos e o jogo de saberes de cientistas e de engenheiros.

Das observações sobre como se faz tecnociência, a experiência de trabalho de campo de Latour o inspira a desenvolver sete regras metodológicas, as quais servem como diretrizes para pesquisar a produção do conhecimento em ciência e tecnologia. De acordo com a primeira regra, tal empreendimento é mais bem sucedido ao analisar a tecnociência em sua dimensão processual, quer dizer, no exato momento em que as controvérsias geradas pelos discordantes reabrem a discussão entre cientistas e engenheiros sobre determinadas afirmações, o que poderá resultar ou não em um novo fato, isto é, em coisa acabada, pronta para ser difundida na sociedade.

A segunda regra, por sua vez, resulta do entendimento de que uma teoria ou um equipamento bem-sucedido não depende exclusivamente dos atributos que possui, mas do julgamento que a sociedade faz desses bens. Significa dizer que a última palavra sobre o que cientistas e engenheiros produzem é dada pela sociedade, a qual pode legitimar, ou não, os produtos da tecnociência na vida cotidiana. Nesse sentido, Latour evidencia sua associação ao perspectivismo mertoniano, admitindo que a Ciência não é um sistema autônomo em relação à sociedade na qual se desenvolve, e para a qual produz conhecimento científico e tecnológico. 
Resenha - Ciência e tecnologia no olhar de Bruno Latour.

Por sua vez, a terceira regra metodológica corresponde ao entendimento de que são as controvérsias que geram as representações da natureza. Para Latour, na tecnociência, o conhecimento científico surge no laboratório, sendo o resultado de certos procedimentos sujeitos à reprodução pelos membros da comunidade científica, os quais disputam entre si pelo melhor discurso capaz de explicar o mundo natural. Esse discurso, ao ser socialmente validado, encerra as controvérsias e converte-se em asserções cientificamente indiscutíveis, que passam a ser difundidas na sociedade como um conhecimento legítimo, até que um discordante reabra as controvérsias pela replicação malsucedida do método.

Simétrica à terceira, a quarta regra diz respeito ao foco de atenção do pesquisador, que não deve ser deslocado da natureza para a sociedade. Neste sentido, a causa da resolução de uma controvérsia científica não está na sociedade em si, pois, para Latour, os condicionantes sociais não determinam os fatos, senão os recursos humanos e não humanos simetricamente envolvidos em sua construção. O caso do engenheiro alemão Rudolf Diesel (1858-1913), que se dedicou exaustivamente à busca por um motor de combustão interna perfeito no século XIX, ilustra essa premissa, haja vista que as lacunas técnicas do projeto só foram solucionadas no tempo e no espaço, à medida que outros engenheiros e empresas como a Maschinenfabrik (MAM) e a Krupp aperfeiçoaram o modelo proposto em um produto eficiente; um artefato socialmente aceito e incorporado à sociedade.

$\mathrm{Na}$ referência a Diesel, novamente é possível perceber a ressonância do pensamento de Merton na obra de Latour. Trata-se do entendimento compartilhado de que em uma mesma época, e em diferentes partes do mundo, cientistas e engenheiros produzem as chamadas descobertas múltiplas. Conforme observa Latour: "Milhares de engenheiros estavam ao mesmo tempo à procura de um motor de combustão mais eficiente. O primeiro lampejo de intuição não poderia estar em uma mente apenas, mas em muitas" (LATOUR, 2011, p. 166). Assim, tanto para Merton quanto para Latour, a visão tradicional de Ciência como prática que resulta no acúmulo progressivo de conhecimento científico é substituída pela compreensão de um processo dinâmico e sincrônico, abrindo espaço para as coincidências inovadoras na tecnociência. 
Resenha - Ciência e tecnologia no olhar de Bruno Latour.

No capítulo quarto de Ciência em ação, a quinta regra metodológica de Latour remete à pergunta: quem são efetivamente os atores que fazem Ciência? Para ele, há uma diversidade de sujeitos envolvidos nesse processo, do qual apenas uma pequena fração corresponde aos cientistas propriamente ditos. Neste ponto, a atividade científica não se resume aos trabalhos realizados dentro dos laboratórios, mas, amplia-se para fora deles. Para quem faz Ciência há, segundo Latour, uma intensa articulação externa, um esforço comunicativo e negociador, a fim de que engenheiros e cientistas alinhem seus objetivos - ainda que indiretamente - aos interesses de outros atores como professores, advogados, empresários e financiadores tidos como um "mal necessário". Destarte, a quinta regra de Latour expressa que o pesquisador deve disciplinar sua observação tanto para dentro quanto para fora do laboratório, de maneira que possa identificar o maior número possível de atores que participam do processo de fazer Ciência.

A noção de rede é introduzida por Latour no quinto capítulo, em que estende a análise da tecnociência para os sujeitos que, embora não façam parte de seus "fios" e "malhas", de uma forma ou de outra a ela se relacionam. Esse significativo número de indivíduos que está do lado de fora da rede conforma uma multidão de atores, que dia após dia é capaz de produzir discursos para a/ou sobre ciência e tecnologia. Entendidos como julgamentos irracionais, tais discursos se convertem em um desafio à racionalidade da atividade científica e tecnológica que, acima de tudo, almeja tornar seus produtos em algo universalmente crível. Na visão de Latour, esse problema se resolve com uma rede espiralada, pela qual o deslocamento de cientistas e de engenheiros no sentido laboratório/sociedade/laboratório é um movimento que associa e mescla interesse/desinteresse, irracionalidade/racionalidade.

É da relação observada entre o mundo de dentro dos laboratórios e o mundo de fora que emerge a sexta regra metodológica. Para Latour, o pesquisador de tecnociência deve concentrar esforços não na busca das causas da irracionalidade discursiva da multidão, mas, ater-se ao movimento e à extensão da rede. Só assim é possível compreender como o que está dentro e o que está fora em algum momento se tocam, se modificam e se complementam, de maneira que as fronteiras entre quem faz tecnociência e sociedade sejam percebidas como algo cada vez mais tênue na contemporaneidade. Latour ilustra esse ponto de vista ao citar o capitão 
Resenha - Ciência e tecnologia no olhar de Bruno Latour.

Lapérouse, que em 1787 desembarcou em Sacalina, no Pacífico, com o propósito de verificar se o local consistia em uma ilha ou em uma península. Auxiliado pelos nativos, o capitão obteve um mapa satisfatório e confirmou tratar-se de uma ilha. Como bem coloca Latour, a experiência de Lapérouse mostra a diferença mínima que existe entre o conhecimento da multidão e o conhecimento de cientistas e de engenheiros, pois a "geografia implícita" dos ilhéus possibilitou, a posteriori, a "geografia explicitada" nas cartas náuticas utilizadas pelos navegadores estrangeiros.

No capítulo final de Ciência em ação, é a ideia de movimento que sustenta o discurso de Latour sobre a produção do conhecimento em rede. Por movimento, ele se refere às aproximações e aos distanciamentos em relação ao trabalho que se processa dentro (centro) e fora (periferia) dos laboratórios. Um ir e vir que resulta no conteúdo propriamente dito da Ciência, produzido por determinados métodos, e registrado em documentos que podem ser combinados de diferentes maneiras no fazer de cientistas e de engenheiros. $O$ deslocamento do cientista no tempo e no espaço é necessário para que se conheça o mundo de fora do laboratório, coletando dados e evidências que são acumulados e convertidos em representações da realidade, as quais Latour denomina informações ou formas. Sem elas seria impossível a construção de modelos reduzidos do mundo de fora, bem como a ampliação da rede pelas conexões entre elementos humanos e não humanos. Assim, na sétima regra metodológica, Latour recomenda que os estudos de laboratório busquem compreender também como a documentação é produzida, codificada, combinada e interligada por meio desse movimento de ir e de vir, inerente à tecnociência. Para ele, é a documentação em seu aspecto burocrático que viabiliza que os resultados das atividades de cientistas e de engenheiros viagem longas distâncias, propagando-se pela multiplicidade de fios e de malhas que formam uma grande rede de saberes.

Como se verifica, em Ciência em ação Latour ajuda a compreender a ciência e a tecnologia como construções sociais. Portanto, como práticas permeadas pelas colaborações de diferentes atores, sejam estes cientistas, engenheiros ou não. Em que pesem as críticas quanto ao esforço de instituir uma antropologia da Ciência, ou, ainda, ao elevar seres humanos e não humanos à condição indistinta de atores que estão a interagir em rede, entende-se que o mérito do trabalho de Bruno Latour 
Resenha - Ciência e tecnologia no olhar de Bruno Latour.

está no conjunto das reflexões e das inferências que é capaz de produzir sobre ciência e tecnologia, graças à experiência adquirida como observador in loco.

Desse modo, ao se pensar em outros autores que marcam presença nos estudos da comunidade científica e de suas práticas, a exemplo de Merton, Kuhn e Bourdieu (1930-2002), que produziram olhares de fora para dentro, Latour segue os passos de Harry Collins (1943- $)^{2}$. Partindo do interior do laboratório, ele convida o leitor a olhar a ciência e a tecnologia de uma posição privilegiada, adotando uma perspectiva de dentro para fora. Isso faz de Ciência em ação uma leitura recomendada não somente aos interessados pela Sociologia, pela Antropologia e pelos Estudos Sociais da Ciência (Social Studies of Science), mas também, a estudantes e a pesquisadores da Comunicação, da Ciência da Informação e de áreas afins.

Uma recomendação que se justifica não só pela discussão sobre o papel da literatura especializada na difusão dos produtos da tecnociência (o que faz precisamente no capítulo segundo). Mas também pela noção que Latour constrói de rede como uma ampla e complexa estrutura humana e não humana, que viabiliza a produção e a circulação do conhecimento. Tal enfoque permite refletir, entre outras coisas, sobre a relação entre indivíduos, informações, documentos, instituições e máquinas no processo de fazer tecnociência. Aspectos, aliás, que assumem papel seminal na compreensão da sociedade contemporânea, em que diferentes atores sociais têm cada vez mais utilizado as redes como recursos estratégicos para a colaboração criativa e, portanto, para a inovação científica e tecnológica.

Recebido em: 20.05.2013

Aceito em: 02.07.2013

2 Conforme Pestre (1996), o sociólogo inglês Harry Collins é um dos pioneiros nos estudos de laboratório, dedicando-se ao trabalho de compreender como os cientistas negociam os chamados "fatos científicos". Ver: PESTRE, Dominique. Por uma nova história social e cultural da ciência: novas definições, novos objetos, novas abordagens. Cadernos IG-UNICAMP, Campinas, v. 6, n. 1, p. 3-56, 1996. Disponível em:

<http://www.ige.unicamp.br/site/aulas/120/PESTRE_Cad_IG_UNICAMP.pdf>. Acesso em: 10 maio 2013. 